\title{
Developing plurilingual competences in primary education
}

Alicia Chabert

chabert@uji.es 
I. Abstract

\begin{abstract}
I. Abstract
Now more than ever the English language has become a necessity in several aspects of our life. As a consequence of globalisation and the need of an international and intercultural communication tool (Jenkins, Cogo, and Dewey 2011, Cogo 2012), English has emerged as a lingua franca and English acquisition is in the spotlight. This research aims to understand how English teaching could be improved at school. While different language approaches and methodologies are used, the mother tongue of the learner is not taken into account in English teaching and the CEFR (Common European Framework of Reference for Languages) is still used as guideline, not only in Europe but also worldwide (Nakatani 2012). We live in a multilingual world where all languages are in constant contact and identities are blurred, mostly when English has raised as the universal language. Taking this into account, our research focuses on a plurilingual approach to English language teaching in order to improve English learning in primary school based on an understanding of languages from an ecological point of view. The study is conducted in five primary school centres, in 3 different countries.
\end{abstract}

Keywords: plurilingualism, multilingualism, linguistic ecology, lingua franca, plurilingual competence, foreign language acquisition.

\title{
II. Context of this research and literature review
}

\section{A dichotomy: English as a lingua franca and multilingualism}

English is the dominant language of the $21^{\text {st }}$ century, with 379 million native speakers (Statista 2019) and approximately 1.75 billion users, which represents approximately a quarter of the world's population (British 2013). The British Council estimates that there are 2 billion people using English in their daily life, or at least learning to use it. This increase in English language speakers is one of the consequences of globalisation, along with the rapid evolution of technology (telephones, the media, internet...) and it is intrinsically linked to English becoming a lingua franca (ELF).

Firth (1996) first defined ELF as a "contact language» between people with different mother tongues and who chose English as their foreign language of communication. However, most researchers now believe native speakers should be included in the ELF paradigm (Friedrich and Matsuda 2010, Jenkins, Cogo, and Dewey 2011, Seidlhofer 2011). Seidlhofer (2005) included native speakers of 
English for whom ELF is also an additional language, understanding ELF as intercultural communication. We understand ELF as the best approach to English learning in a multilingual society taking that the language is taught without associating it necessarily to a specific culture. In this vein, House (2003) distinguishes between 'languages for communication' and 'languages for identification'.

In this moment in history, with immigration, ease to travel, social networks and the internet, among other reasons, the lines between languages in use and identities are blurred and constantly changing. Cultural and linguistic diversity, multilingualism and plurilingualism are among the key values of Europe, however the guidelines for English teaching keep having a monolingual approach, which contradicts its own recommendations for plurilingualism and multilingualism. The Council of Europe makes a distinction between the linguistic diversity of a geographical region, which is referred to as multilingualism, and the linguistic competence of an individual, also known as plurilingualism. However, both terms are usually interchanged and most of the time we will find that the most common term is multilingualism, referring to the linguistic diversity of both individual and geographical region. We will, nevertheless, keep the distinction between the two.

The Common European Framework of Reference for Languages: learning, teaching, assessment (Council of Europe 2001 - henceforth CEFR) is the current language guidelines used not only in Europe but also worldwide. It was originally designed to describe the language learners' abilities at different stages of their learning and to be language-neutral, so it could be applied to any foreign language learning situation. Because of its neutral nature, this framework does not take into account the different mother tongues the learners have, which impact the strengths and weaknesses of each student, so "the practice of applying the CEFR has mostly neglected the dimension on plurilingualism and plurilingual competence» (Kalliokoski 2011, 87). Nevertheless, plurilingualism has now become an unavoidable factor to take into account in most research and it has been introduced in the CEFR. Plurilingualism is presented in the CEFR as a changing competence, in which the learner's resources in one language or variety may be very different in nature to those in another (Council of Europe 2018), However the monolingual immersive approach to foreign language teaching is still recommended.

\section{Monolingual and plurilingual approaches to foreign language acquisition}

In the field of English language teaching, the monolingual approach has been appointed as the official approach to be applied in English classes. Even though, literature and research suggests that 
it has been a questionable approach for years and that a plurilingual approach could be more beneficial for English learning.

For decades, there has been a main focus on major exposure to L2 and the importance of a native speaker teacher in the English classroom. In fact, while the perception in some countries is changing, in many others the non-native English teachers are still positioned as deficient speakers of the language, with imperfect knowledge of the foreign language and culture (Walkinshaw and Oanh 2014). Regardless of the nativeness of the teacher, the use of the mother tongue in the classroom has been very controversial for decades. From Selinker's (1972) definition and understanding of interlanguage as a separate linguistic system in which the learner fossilizes errors due to similarities with the native language and this prevents the person from achieving a full level of facility in the use of the target language, many theories were introduced on how the first language (L1) influenced the second language (L2) learning negatively. As Selinker, many researchers supported this view of L1 being a detrimental 'interference' to L2 learning (Lado 1957, James 1980, Flege and Davidian 1984, Yu 2009). Nevertheless, soon enough scholars started proving how the $\mathrm{L} 1$ could be used as an instrumental tool to favour L2 learning (Cook, Long, and McDonough 1979, Wells 1999, Cook 2001, Lasagabaster 2001, Herdina and Jessner 2002, Jessner, De Angelis, and Kresic 2015), and slowly but surely there has been a recent shift towards this approach in which mother tongues are positive to subsequent language learning. This research shift has focused on using languages to learn other languages, i.e. developing the plurilingual competences of the students to use languages as a strategic competence. The Council of Europe refers to this competence as the repertoire of resources which the students acquire in all the languages they know or have learned, and the cultures associated with them (Beacco et al. 2016). So much evidence has been provided in literature that whether using L1 on L2 learning is not the focus of the debate anymore, but how to use L1 in a way that will be beneficial to second language learning.

Despite plurilingualism being recommended by the Council of Europe and by linguistic specialists, the common belief of the English-only classroom still prevails in teachers and parents of students. Europe has been promoting linguistic diversity and general guidelines on plurilingualism without real application, which has resulted in confusion and programmes that claim to be plurilingual but in which a plurilingual approach is still lacking, as it can be observed in the Plurilingual Plan in the Valencian Region.

The Plurilingual Plan is a new program that has been implemented in the past couple of years in the Valencian Region and involves the division of subjects by language so that the students are exposed to three languages in different contexts: Spanish, Catalan 
and English. The goal of this program is to maximise the communicative competence in different languages by creating contexts in which those languages are to be used. However, while this program focuses on increasing the opportunities to use a certain language, it is still focused on a monolingual approach since it does not allow more than one language to be used in a specific setting and keeps all languages as separate units understanding them as if they do not interact with each other. Even though this programme claims to be plurilingual, it fails to use a plurilingual approach.

\section{Objectives of our study}

Our research aims to describe how the English language is spreading in our multilingual reality and analyse how the current language policies and guidelines are implemented. At the same time, we propose a plurilingual approach that is tested in different countries with the purpose of demonstrating how English teaching could be improved taking into account the mother tongue of the students and using an ecological linguistic approach, so English is learnt as a communicative tool and not an identification instrument that devalues different cultures and languages.

The ecology of language is a metaphor first used by Haugen (1972) to describe the relationships among the diverse forms of language in the world and the groups of people who use them. We will use this concept as part of the approach we propose, that is, a plurilingual approach that values each language for the learning of a subsequent language. We consider essential that students gain knowledge and understanding of different languages so that they develop social and intercultural understanding, but in order to achieve this, plurilingualism needs to be promoted in the classroom. Despite the different views on cross-linguistic influence, it has been demonstrated that the interaction among language systems in a plurilingual speaker develops a high level of awareness of languages (Jessner 2006). In our international study we aim to demonstrate how the interaction of languages facilitates the learning in a subsequent language.

To put simply, our research objectives are as follows:

- Comparing how the mother tongue influences English learning differently in each country (Norway, China and Spain participate in this research).

- Arguing that, if the mother tongue influences learning English, the teaching methodology should be adapted accordingly.

- Demonstrating that a plurilingual approach is always more beneficial than a monolingual one in a primary school setting. 
- Demonstrating that using an ecological linguistic approach while learning English will provide the students with the understanding of English as an international communication tool separate to the value of the mother tongue a an identification tool. In Seidlhofer's words, we need to change the monolingual view of English as a property of its native speakers "to the recognition of ELF as an appropriated communicative resource, its use characterized by continuous negotiation of meaning and linguistic adaptation and plurality».

In order to meet our objectives, we are carrying out an international study that includes speakers of a roman language (Spanish), Scandinavian language (Norwegian), and Asian language (Chinese). This study focuses on the learning of primary school students and aims to understand their attitudes towards English and their mother tongue, as well as the objectives above stated.

\section{Research design: method and participants}

Five centres participate in this study: three in the Valencian Region, one in Norway and one in China. While our initial proposal was to have the same amount of schools in every country, due to the lack of response and willingness to participate we were only able to secure one in Norway and one in China, in comparison to the three we have in the Valencian Region. This issue will be included in the limitations of our study.

In terms of participants, we focused on the $6^{\text {th }}$ year of Primary School and the groups include between 20 and 30 students (this is specified in each segment of the experiment). As for methodology, we use experimental research along with survey, so we use a mix of quantitative and qualitative approaches. The process has been carried out as follows:

- 2016 to 2017 - Literature review and research.

- 2017 to 2018 - Surveys to parents and students, pilot test and interviews to teachers.

- 2018 to 2019 - Full study on the three countries participating in the study, questionnaires to the students and analysis of all obtained results.

All the results will be analysed within the current frameworks and guidelines, as well as the countries linguistic and education policies. We will also compare the different policies between Europe and Asia (ASEAN+3 countries $^{1}$ ).

In 2017 we carried out the pilot study, for which we used a monolingual approach in the control group and a plurilingual

\footnotetext{
${ }^{1}$ Association of Southeast Asian Nations including Indonesia, Malaysia, Philippines, Singapore, Thailand, Brunei, Myanmar, Cambodia, Laos and Vietnam, plus China, South Korea and Japan
} 
approach in the experimental group. In order to test the experiment in different countries, we conducted the study in one of the centres participating from Spain and the centre participating in Norway. Before carrying out the study we interviewed the teachers to learn about the students' background, their general behaviour and the style used in the classroom. Afterwards, we chose a topic and grammar concept that coincided in both books (Norwegian and Spanish) and the students had not yet studied, which in this case was the past continuous. For the monolingual approach we used only English for instruction, explanation and communication. On the other hand, for the plurilingual approach we used the mother tongue of the students when needed for instruction and we compared English and the mother tongue when explaining grammar concepts (in Norway we received help of the Norwegian teacher in the classroom for this purpose). After this we examined the students using exercises based on the new concepts and grammar learnt. The exercises used as a test included three activities: fill the gaps activity (comprehension-production), identification of concept in a reading activity (comprehension) and creation of sentences using the concept explained in class (production). In both countries we obtained better results using a plurilingual approach (see Chabert 2017).

Surveys were carried out in the classroom focusing on whether the students received any English tutoring after school, the amount of time they spent watching TV or movies in English, their feelings about their mother tongue and English and their opinion on whether they believe they learn better when the class is taught fully in English or in English and their mother tongue.

Based on this first process, we realised that it would be very interesting to include an oral part of the activity and analyse the plurilingual competence in speaking as well as writing. For this reason, in the main study we modified the approach as follows:

- Two sessions are held in each group (control and experimental group per centre).

- In the first session, a new concept is explained and practised. At the end of the class the students do the test about the specific subject (as with the previous pilot test, in one class we use a plurilingual approach and monolingual in the other).

- In the second class we review the concept explained in the first class and record the audio of the whole class. A role play activity is carried out in couples.

- This time the concept and unit chosen to be explained and used in the test were: the imperative, giving and receiving directions and prepositions of place and movement. 
- After the activities, students were requested to fill in a questionnaire to gather information about their backgrounds and their affective filters when learning English.

In terms of the activities to be analysed in this study, we included a comprehension activity, a fill the gaps and a production exercise. As for the role play: the students are partnered in couples. One of them acts as him/herself, the teacher acts as a foreigner who is lost and the second student is the grandparent of the student. The students enact a situation in which they are going to the market and encounter a lost foreigner that is asking for directions. The foreigner (who, for the purpose is not a native English Speaker) asks for help to the grandparent but he/she does not speak English, so the student acting as him/herself will intervene. This activity is done in both experimental and control groups, however in the experimental group the student is allowed to use a little Spanish if they get stuck (up to 3 words). The specific situation of this role play is purposeful, so the foreigner is in this case a German speaker, so she does not use English only. The reason for this is to show that it is okay to use a different language to express yourself if the English terminology is not readily available and also to see that we can draw from other languages to understand other languages (similarities between languages). On the other hand, by bringing a guardian figure (grandparent/parent) and actually using language to help them motivates the students, gives them a sense of autonomy and relevance. This fact is also then tested after the activity by asking the students about what they would do in this situation. In the experimental group, the students are allowed to use a little of their mother tongue to show them that is better to say something in their mother tongue than getting stuck or being scared of saying something wrong. By audio recording this, we analyse if the fluency is affected when the option of using a few words in their mother tongue is given.

At the moment we have the results of the pilot test and two of the schools in Spain. The study in the third school is programmed to start in February 2019, the study in Norway will take place in January 2019 and in China in April 2019. Once all the results are available we will analyse them individually and compare them, taking the current educational guidelines of the relevant country into account.

\section{Results and expectations}

During the pilot test we achieved better results in all activities and both countries when using a plurilingual approach. See below figure 1 for reference: 


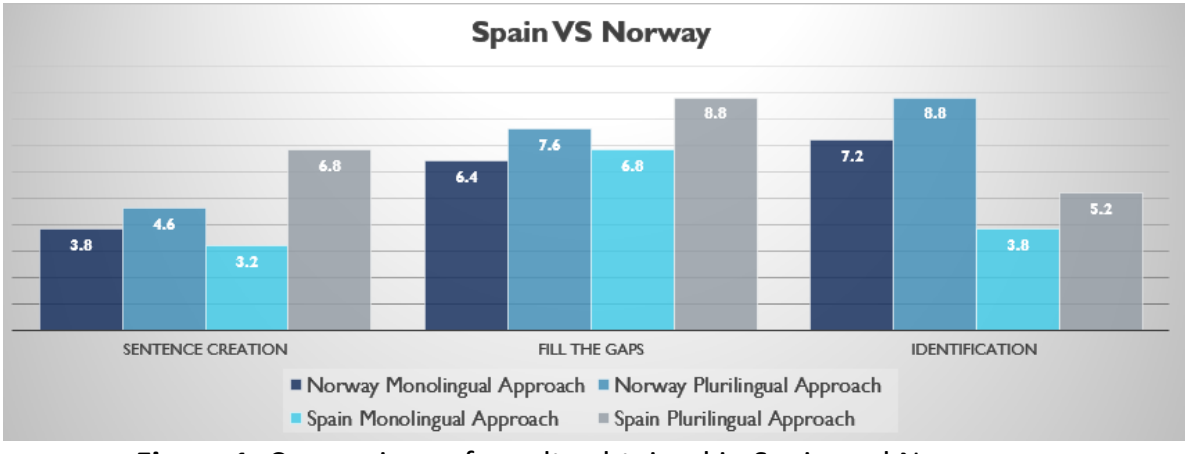

Figure 1. Comparison of results obtained in Spain and Norway

Also in the first test, we questionnaires were administered to parents regarding their preference on language use in the classroom and, interestingly, $100 \%$ of the parents in the Spanish school believed only English should be used in the classroom, whereas $97.3 \%$ of the parents in the Norwegian school believed both Norwegian and English should be used in the classroom. We found this information relevant taking into account that Norway has a very high level of proficiency (see EF EPI index ${ }^{2}$ ) in English as compared to Spain, and yet they use their mother in their classes.

Regarding the current main study, based on the pilot study and the first results obtained in the two schools already tested, we expect students to achieve better results in the activities when both English and their mother tongue are used in the classroom. We further expect students to be more confident in English when the use of their mother tongue when needed is not punished, as per the results on the first schools, and we believe the role play activity will provide student with a sense of autonomy, accomplishment and positive attitude towards languages (including their mother tongue).

\section{Conclusion and limitations}

As above mentioned, based on the results of the pilot study, and the first results obtained, a plurilingual approach is shown to achieve better results in English learning. Our study supports the theory that the $L 1$ is deeply involved in subsequent language learning and that fostering plurilingual competences will teach the students to use L1 in a strategic way to navigate the voids in $L 2$ knowledge and progress in it accordingly. In this way, teaching all languages as part of a communication system would develop strategic competences that would facilitate learning in any language. Also, by teaching English from an ecological perspective in which English is not associated with prestige but with international and intercultural communication between people in a globalised world, the preservation of cultures and languages would thrive.

\footnotetext{
${ }^{2}$ https://www.ef.com/wwen/epi/
} 
It is important to note, as part of our limitations, that all variables in this international study need to be considered in terms of: mother tongue, socio-economic background, bilingualism of the students, rural vs. urban area, and tutoring outside school. Also, further testing (from a longitudinal perspective) would be needed to check the impact of the long-term application of a plurilingual approach. Nevertheless, this study significant in promoting and examining the concept of plurilingual competence as established by the Council of Europe, which is believed to be necessary to accompany linguistic policies (Coste, Moore, and Zarate 2009).

\section{References}

Beacco, Jean-Claude, Michael Byram, Marisa Cavalli, Daniel Coste, Mirjam Egli Cuenat, Francis Goullier, and Johanna Panthier. 2016. Guide for the Development and Implementation of Curricula for Plurilingual and Intercultural Education. Brussels: Council of Europe.

British, Council. 2013. The English Effect. The impact of English, what it's worth to the UK and why it matters to the world. London: The British Council.

Chabert, Alicia. 2017. "La influència de la llengua materna en l'aprenentatge d'anglés arreu del món.» Fòrum de Recerca 22.

Cogo, Alessia. 2012. «English as a Lingua Franca: concepts, use, and implications.» ELT Journal 66 (1): 97-105. doi: 10.1093/elt/ccr069.

Cook, Vivian. 2001. "Using the First Language in the Classroom.» The Canadian Modern Language Review 57 (3): 402-423. doi: 10.3138/cmlr.57.3.402.

Cook, Vivian J., J. Long, and Steven McDonough. 1979. «First and second language learning." In The Mother Tongue and Other Languages in Education, edited by George E. Perren. London: Centre for Information on Language Teaching.

Coste, Daniel, Danièle Moore, and Geneviève Zarate. 2009. Plurilingual and Pluricultural Competence - Studies towards a Common European Framework of Reference for language learning and teaching. Brussels: Council of Europe.

Council of Europe. 2018. Common European Framework of Reference for Languages: Learning, Teaching, Assessment Companion Volume with New Descriptors. Brussels: Language Policy Programme.

Firth, Alan. 1996. "The discursive accomplishment of normality: On 'lingua franca' English and conversation analysis.» Journal of 
Pragmatics 26 (2): 237-259. doi: 10.1016/0378-2166(96)00014-

8.

Flege, James Emil, and Richard D. Davidian. 1984. "Transfer and developmental processes in adult foreign language speech production." Applied Psycholinguistics 5 (4): 323-347. doi: 10.1017/S014271640000521X.

Friedrich, Patricia, and Aya Matsuda. 2010. «When Five Words Are Not Enough: A Conceptual and Terminological Discussion of English as a Lingua Franca.» International Multilingual Research Journal 4 (1): 20-30. doi: 10.1080/19313150903500978.

Haugen, Einar. 1972. The ecology of language. Stanford: Stanford University Press.

Herdina, Philip, and Ulrike Jessner. 2002. A Dynamic model of multilingualism: perspectives of change in psycholinguistics. Clevedon: Multilingual Matters.

House, Juliane. 2003. "English as a lingua franca: A threat to multilingualism?» Journal of Sociolinguistics 7 (4): 556-578.

James, Carl. 1980. Contrastive analysis. London: Longman.

Jenkins, Jennifer, Alessia Cogo, and Martin Dewey. 2011. «Review of developments in research into English as a lingua franca.» Language Teaching 44 (3): 281-315. doi: 10.1017/S0261444811000115.

Jessner, Ulrike. 2006. Linguistic Awareness in Multilinguals: English as a Third Language. Edinburgh: Edinburgh University Press.

Jessner, Ulrike, Gessica De Angelis, and Marijana Kresic. 2015. Crosslinguistic influence and crosslinguistic interaction in multilingual language learning. New York: Bloomsbury Academic.

Kalliokoski, Jyrki. 2011. «Plurilingual competence, Styles and Variation.» Journal of Estonian and Finno-Ugric Linguistics 2 (2): 87-110.

Lado, Robert. 1957. Linguistics across cultures; applied linguistics for language teachers. Ann Arbor: University of Michigan Press.

Lasagabaster, David. 2001. "The Effect of Knowledge About the L1 on Foreign Language Skills and Grammar.» International Journal of Bilingual Education and Bilingualism 4 (5): 310-331. doi: 10.1080/13670050108667735.

Nakatani, Yasuo. 2012. «Exploring the Implementation of the CEFR in Asian Contexts: Focus on Communication Strategies.» Procedia.Social and Behavioral Sciences 46: 771-775. doi: 10.1016/j.sbspro.2012.05.196. 
Seidlhofer, Barbara. 2005. "English as a lingua franca.» ELT Journal 59 (4): 339-341. doi: 10.1093/elt/cci064.

Seidlhofer, Barbara. 2011. Understanding English as a Lingua Franca. Oxford: Oxford University Press.

Selinker, Larry. 1972. "Interlanguage.» International Review of Applied Linguistics in Language Teaching 10 (1-4): 209-232. doi: 10.1515/iral.1972.10.1-4.209.

Statista. 2019. The most spoken languages worldwide (native speakers in millions). Hamburg.

https://www.statista.com/statistics/266808/the-most-spokenlanguages-worldwide/.

Walkinshaw, lan, and Duongthi Hoang Oanh. 2014. "Native and NonNative English Language Teachers.» SAGE Open 4 (2). doi: $10.1177 / 2158244014534451$.

Wells, Gordon. 1999. "Using L1 to Master L2: A Response to Anton and DiCamilla's "Socio-Cognitive Functions of L1 Collaborative Interaction in the L2".» The Modern Language Journal 83 (2): 248-254. doi: 10.1111/0026-7902.00019 Cit.

$\mathrm{Yu}$, Xiaoping. 2009. "The Negative Transfer of Mother Tongue in Non-English Majors' Compositions from the Perspective of Syntax.» Asian Social Science 5 (9): 137-141. 